Wilfrid Laurier University

Scholars Commons @ Laurier

Kinesiology and Physical Education Faculty

Publications

Kinesiology and Physical Education

$1-2000$

\title{
Age and Physical Activity Among Canadian Women and Men: Findings From Longitudinal National Survey Data
}

James Curtis

University of Waterloo

Philip White

McMaster University

Barry McPherson

Wilfrid Laurier University, bmcpherson@wlu.ca

Follow this and additional works at: https://scholars.wlu.ca/kppe_faculty

\section{Recommended Citation}

Curtis, James; White, Philip; and McPherson, Barry, "Age and Physical Activity Among Canadian Women and Men: Findings From Longitudinal National Survey Data" (2000). Kinesiology and Physical Education Faculty Publications. 1.

https://scholars.wlu.ca/kppe_faculty/1

This Article is brought to you for free and open access by the Kinesiology and Physical Education at Scholars Commons @ Laurier. It has been accepted for inclusion in Kinesiology and Physical Education Faculty Publications by an authorized administrator of Scholars Commons @ Laurier. For more information, please contact scholarscommons@wlu.ca. 
Journal of Aging and Physical Activity, 2000, 8, 1-19

Q 2000 Human Kinetics Publishers, Inc.

\title{
Age and Physical Activity Among Canadian Women and Men: Findings From Longitudinal National Survey Data
}

\begin{abstract}
James Curtis, Philip White, and Barry McPherson
This study reports on age-group differences in leisure-time sport and physical activity involvement among a large sample of Canadians interviewed at 2 points during the 1980s. Comparisons are made for 5 age cohorts, for men and women, and without and with multivariate controls. The results contradict the usual finding of an inverse relationship between age and level of physical activity. On measures of (a) activity necessary to produce health benefits and (b) energy expenditure, Canadians over 65 were as active as, or more active than, their younger counterparts, and their activities did not decline over the 7 years between interviews. The extent of change varied by age and across women and men. Among women, increases in involvement were greatest in the middle-aged. Among men, the greatest increase was in the oldest age groups. For both genders, the youngest age cohort showed the smallest change over time, and there was evidence of slight declines in activity levels among young men.
\end{abstract}

Key Words: age, Canada, gender, physical activity

In Canada, as in various other nations, the demographic shift toward an aging population and the long-term trend toward a greater life expectancy have led to heightened demand for an enhanced quality of life in the later years. One of the factors seen as important in achieving this greater quality of life is physical activity. For example, increasing attention is being paid to the role of physical activity and exercise in improving and maintaining health and enhancing both physical and cognitive functioning (e.g., see the reviews in Bouchard, Shephard, \& Stephens, 1994; Bouchard, Shephard, Stephens, Sutton, \& McPherson, 1990; Chogahara \& Yamaguchi, 1998; Curtis \& Russell, 1996; Orban, 1991; Quinney, Gauvin, \& Ted Wall, 1994; Russell, 1997; and Spirduso, 1995).

Nonetheless, cross-sectional studies of adults in Canada and other countries show that involvement in sport and exercise activity tends to decline with age,

James Curtis is with the Department of Sociology at the University of Waterloo, Waterloo, ON, Canada N2L 3G1. Philip White is with the Department of Kinesiology at McMaster University, Hamilton, ON, Canada L8S 4K1. Barry McPherson is the Dean of Graduate Studies at Wilfrid Laurier University, Waterloo, ON, Canada, N2L 3C5. 
particularly for women (e.g., Bokovoy \& Blair, 1994; Curtis \& White, 1984; Drinkwater, 1994; Dumazedier, 1973; Hobart, 1975; McPherson, 1978, 1998; McPherson \& Kozlik, 1987; O'Brien Cousins \& Keating, 1995). However, there is also some evidence that, overall, levels of physical activity have increased in some societies (e.g., Stephens \& Caspersen, 1994). This change has been attributed to, among other factors, efforts by governmental and other agencies to promote active and healthy living (see, e.g., Blair, Brill, \& Barlow, 1994; Bouchard et al., 1994; Drinkwater, 1994; Fitness Canada, 1992; Hagberg, 1994; Malina, 1994; McAuley, 1994; Paffenbarger, Hyde, Wing, Lee, \& Kampert, 1994; Quinney et al., 1994). The goals of these public health-promotion programs, such as the Active Living program in Canada, include increased quality of life, decreased risk of mortality, reduction in the onset of risk factors for disease, and elevated feelings of subjective well-being from physical activity (e.g., Bokovoy \& Blair, 1994; Buskirk, 1990; Curtis \& Russell, 1996; Spirduso, 1994).

At present, because most of the relevant previous research on age and physical activity was conducted with cross-sectional survey data rather than longitudinal survey data, there is little direct evidence concerning patterns of change in activity for individuals over time. In particular, the extent to which different age cohorts have increased (or decreased) their levels and intensity of physical activity over time is not well understood. Of course, panel study data-from the same individuals being studied at two or more points in time-are required if we wish to know how individuals of different ages have changed over time.

Malina (1996) recently summarized the results of available panel studies of physical activity. He showed that (a) few studies cover a very long time span in the life cycle, and there is little attention paid to late adulthood; (b) the studies involve differing types of samples, generally convenience samples; and (c) they have greatly varying indicators of sport and physical activity and methods of analysis. As a result, correlations of earlier and later involvement in physical activity vary considerably across studies. However, these studies can be juxtaposed to give a tentative picture of effects over the life cycle. When this is done, Malina (1996) reports, "it appears that physical activity tracks at low to moderate levels during adolescence, from adolescence into adulthood and across various ages in adulthood" (p. 55). Also, the longer the period for the age comparison, the lower the correlation.

In this article, we present results from a panel study of a national sample of Canadians interviewed on two occasions 7 years apart. The results offer insight into the physical activity patterns of the various age cohorts over the time course of the study. Our working hypotheses were as follows.

First, based on previous research with cross-sectional data conducted in other countries (e.g., Stephens \& Caspersen, 1994), we expected uncontrolled and multivariate controlled comparisons of age groups to show an overall increase in leisure-time physical activity between 1981 and 1988, the period covered by our longitudinal panel data. We should emphasize at the outset that leisure-time physical activity is, of course, different from physical activity overall. The latter includes activity at work and in daily living. Our data were limited to information on leisure-time physical activity. 
Second, concerning change from 1981 to 1988 across the age cohorts, we wondered whether older or younger Canadians had been most influenced by the promotional messages and other factors directed at increasing people's levels of activity during the decade. There is some reason to hypothesize that increases would have been larger among older people. For example, walking for exercise, which gained greatly in popularity during the 1980 s and 1990 s, seems to have had greater legitimacy among older Canadians than among younger Canadians. Moreover, the various age cohorts likely did not have the same latitude to increase their levels of activity. Some older Canadians, particularly those entering retirement, probably started the study period with comparatively low activity; for this reason, they might have found it easier to increase their involvement. Furthermore, people who are retired probably have fewer competing demands for their time than younger, working-age people do.

At the same time, there are reasons to suppose that younger and middle-aged adults might show more increase in their activity over time. Each of the following developments could have benefited younger Canadians more than their older counterparts: active-living media campaigns, growth in availability of sport and physical activity programs, technologically improved equipment and clothing, and construction of physical activity facilities.

We also expected that, for each of a set of measures of involvement in physical activities, the older age cohorts would be comparatively low in activity in 1981 and 1988 , as has been reported from cross-sectional studies. The leisure-time physical activity levels of older Canadians were likely lower early in the life cycle than those of younger Canadians, currently. The latter are more likely to have had opportunities through the school system and community programs to learn about and be involved in sport and physical activity. Also, older people might have fewer financial resources to apply to activity and poorer availability of facilities and programs than younger people do. Furthermore, lower levels of current physical activity might be expected among older age groups than in younger cohorts because of the effect of physical aging. It is likely that more older people than younger people are physically unable to be active beyond the demands of daily living (see, e.g., Bokovoy \& Blair, 1994; Fletcher \& Hirdes, 1996).

The results of previous studies also suggest that it is advisable to control for the conjoint effects of various factors such as income, education, region of residence, marital status, and employment status in studying age category differences. Each of these factors is generally correlated with age and physical activity involvement (Clark, 1995; Curtis \& McPherson, 1987; Lock \& Wister, 1992; Stephens \& Caspersen, 1994). Therefore, if we wish to estimate direct effects of changes in age status, as opposed to effects of changes in these other factors, controls are necessary. Our data source allowed us to explore age differences in physical activity without and with the controls. Furthermore, as we suggested above, one might expect that health status would not be as good for older Canadians as for the young and the middle-aged, and that poor health reduces the frequency and intensity of physical activity. Therefore, we determined the age patterns in physical activity at each point in time, and for changes over time, without and with controls for the effects of health status. 


\section{Data Sources and Procedures}

\section{DATA SOURCES}

The data sources were the 1981 Canada Fitness Survey and the 1988 follow-up to that survey, the Campbell's Survey on Well-Being in Canada. The two surveys, each designed to elicit information on fitness, health, and well-being among Canadians, constituted a panel study wherein some of the same respondents were interviewed at both points in time. Some families that participated in the 1981 study were randomly chosen to be reinterviewed in 1988. At both points in time, the sampling units were households rather than individuals. The households used in the surveys were selected by a stratified, multistage cluster procedure to ensure representation of individuals from each province and from regions within provinces in 1981. Those living in institutions or remote areas of Canada, amounting to approximately $3 \%$ of the population, were excluded. In the sampling process, each province was divided into geographical areas defined as major city, urban, or rural. Then smaller areas, or segments, were selected from within these geographical areas, and several households were chosen from each segment for interviews. ${ }^{\prime}$

In 1981, data were collected from all members of each selected household older than 6 years of age, using a number of procedures including direct physical measurement, face-to-face interviews, and self-completed questionnaire. A total of 11,884 households and 23,400 individuals responded to interviews or questionnaires in 1981; a subsample of 14,365 respondents also participated in the measurement of physical characteristics. For the follow-up data collection in 1988, 4,258 respondents were listed in the sampling frame. Of these, 312 could not be located, 104 were deceased, and 774 were nonrespondents, yielding a response rate of $72 \%$.

Our data analyses were conducted in two phases. In the first phase, which examined participation in physical activity in 1988, the working sample was reduced to 3,003 respondents after selecting for those who had been adults ( 18 and older) in 1981. Younger respondents were excluded because measurement of change over time would have been confounded by their physical activity during high school at the first point in time. This procedure was followed to provide a benchmark measure of involvement in 1981 for those who were adults at that time. For the second part of our analyses, which examined changes in sport and physical activity over the 7-year period, the working sample included 2,409 respondents who had responded to questions on sport and physical activity in 1981 and again in 1988. The sample was smaller in this second phase of analysis because of sample attrition and failure on the part of some to respond to certain questions at the time of the follow-up survey.

\section{INDEPENDENT AND CONTROL VARIABLES}

The independent variable was age in 1988. This was coded into the following categories: $25-34,35-44,45-54,55-64$, and 65 and over. Gender was employed as a contingency control.

'For further details on the 1981 and 1988 surveys, see Stephens and Craig (1990). Also, Fletcher and Hirdes (1996) have reported in this journal on the relationships of age, selfreported health, and physical activity among those 55 and older in the two studies. 
The following social background factors were introduced as statistical controls in the multivariate analyses: Individual income in 1988 was categorized as less than $\$ 10,000, \$ 10,001-14,999, \$ 15,000-19,999, \$ 20,000-24,999, \$ 25,000-$ $34,999, \$ 35,000-54,999$, or $\$ 55,000$ and over. Province of birth was recoded into four regional categories: eastern Canada, Quebec, Ontario, and western Canada. Marital status in 1988 was coded as married, widowed, divorced/separated, or single. Employment status in 1988 was coded as either employed full- or part-time or not employed. Level of education in 1988 was coded into five categories: some secondary education, secondary diploma, some postsecondary education, community-college diploma, and one or more university degrees. Respondents' perceived health was employed as a control in some of the analyses and was divided into the following categories: very good, good, average, poor, and very poor.

\section{DEPENDENT VARIABLES}

The Index of Level of Activity for Cardiovascular Benefit was a three-category variable constructed by the original researchers both from measures of the intensity of sport and physical activity involvement of respondents and from estimates calculated in the exercise science literature of the exercise "dose" required for cardiovascular health benefit (Stephens, Craig, \& Ferris, 1986; see also Haskell, Montoye, \& Orenstein, 1985). Calculations were based on a daily average of the energy expended in physical activities by individual respondents. ${ }^{2}$ Energy expenditure was estimated by multiplying the number of occasions of involvement by the average time spent per occasion by the METS value for the activity, which is the energy cost of an activity expressed as kilocalories expended per kilogram of body weight per hour of activity $\left(\mathrm{kcal} \cdot \mathrm{kg}^{-1} \cdot \mathrm{hr}^{-1}\right)$. The METS value for each activity was estimated according to previously published procedures (see Stephens \& Caspersen, 1994; Stephens \& Craig, 1985). In the current survey, those who were categorized as "sufficiently active" ( code $=3$ ) had completed an exercise dose requiring at least $3 \mathrm{kcal} \cdot \mathrm{kg}^{-1} \cdot$ day ${ }^{-1}$ at least every other day. "Minimally active" respondents (code $=2$ ) were defined as those averaging $1.5-2.9 \mathrm{kcal} \cdot \mathrm{kg}^{-1} \cdot$ day $^{-1}$. Those averaging under $1.5 \mathrm{kcal} \cdot \mathrm{kg}^{-1} \cdot$ day ${ }^{-1}$ were deemed "sedentary" (code $=1$ ).

The Energy Expenditure Index was also a three-category variable. This variable was similar to the Index of Level of Activity for Cardiovascular Benefit, with the difference that the calculation of the index came from a restricted list of 38 activities that appeared on the 1981 public-use tapes. This list was used by the original researchers in their published work on Canadian physical activity patterns (Stephens et al., 1986).

The third dependent measure, The Index of Organized Activity, was developed by us to assess the degree to which respondents participated in structured or organized physical activity. The variable was constructed by summing the number of positive responses by physically active respondents to three forced-choice questions about the nature of their activity. The questions were (a) "Was this activity scheduled at specific times?" (b) "Was this activity directed by an instructor or supervisor?" and (c) "Was this activity competitive, with organized tournaments,

${ }^{2}$ The measure was calculated for participation in 123 different types of physical activity reported by respondents. 
leagues, or races?" The range of scores for the variable was from 0 (responded negatively to all three questions) to 3 (responded positively to all three questions).

Two other dependent variables were created to measure changes in participation in physical activity from 1981 to 1988 . The measures were computed by subtracting responses given in 1981 to the Index of Level of Activity for Cardiovascular Benefit and the Energy Expenditure Index from the responses to the comparable questions given in 1988. The range of values for both of these indicators of change is from +2 (for a respondent who went from being "sedentary" in 1981 to "sufficiently active" in 1988) to -2 (for a respondent who went from "sufficiently active" to "sedentary" between 1981 and 1988). A similar change measure could not be compiled for organized activity because equivalent questions were not asked at the two points in time.

\section{STATISTICAL PROCEDURES}

The statistical procedure used was multiple-classification analyses (MCA), which is a variant of analysis of variance (Andrews, Morgan, Sonquist, \& Klein, 1973) that assesses the relative effects of several predictor variables on a dependent variable. MCA yields mean scores on each category of the dependent variable, both unadjusted and adjusted, for the effects of each of the predictor variables. MCA analyses are accompanied by an $F$ test for statistical significance and betas measuring the relative effects of predictors and the contribution to variance explained $\left(\right.$ beta $\left.^{2}\right)$ of each predictor variable.

The analyses are presented here in two stages, with each stage involving zeroorder and higher order controlled findings. The first stage was a cross-sectional analysis of physical activity involvement by age in 1988. In the second stage, we computed measures of changes in physical activity involvement from 1981 to 1988.

Because physical activity has often been shown to vary by gender (e.g., for Canada see the results in White \& Curtis, 1990), all the analyses were conducted separately for men and women. We have set aside, for the time being, direct comparisons of women and men, using controls with the merged sample for both genders. Comparisons across the tables presented here show, though, zero-order or uncontrolled comparisons of the activity levels of both genders. Patterns of change by age are shown for each gender.

Controls were introduced in both stages of the analysis in order to separate out the effects of social background factors that, we reasoned, might help explain the relationship between age and participation in sport and physical activity. The findings report mean values on the dependent measures for each age category (a) before controls were introduced, (b) after controls for social background factors only were introduced, and (c) after controls for both social background factors and the measure of health status were introduced.

\section{Results}

\section{PHYSICAL ACTIVITY INVOLVEMENT BY AGE IN 1988}

Table 1 presents the findings for the physical activity levels of adult men in 1988, before and after the introduction of controls. First, before controls, two of the 


\begin{tabular}{|c|c|c|}
\hline * $\begin{array}{r}\text { E } \\
\hat{\varepsilon}\end{array}$ & * $\begin{array}{l}n \\
\hat{o} \\
\hat{\alpha}\end{array}$ & * * \\
\hline 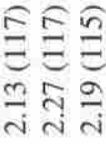 & 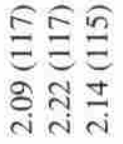 & 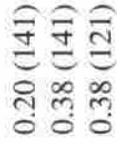 \\
\hline 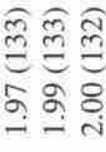 & 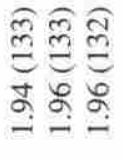 & 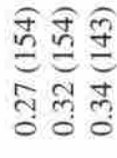 \\
\hline
\end{tabular}

突

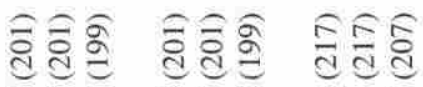

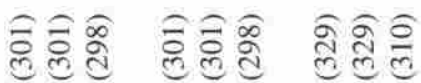

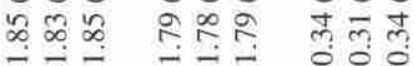

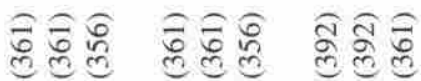
ڤัす

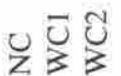

$\cup$
$Z$
3

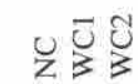

$\equiv \sum_{-i}$

苛

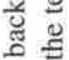

즐 
activity measures show a unilinear positive relationship with age, and the other a linear negative relationship.

After controls for social background factors were introduced, there were significant age-category differences on all three measures of physical activity involvement. For the Index of Activity for Cardiovascular Benefit, the relationship was curvilinear, $\beta=.14, F(4,23)=2.76, p<.05$. Men's activity level was lower in the 45-54-year age group than for younger and older respondents. In fact, on this measure of activity the most active male respondents, both before and after controls were introduced, were over 65 years of age. After the second level of controls was introduced, adding the effects of health status, the relationship between age and physical activity was not statistically significant, although the pattern of findings was similarly curvilinear, $\beta=.11, F(4,27)=1.77$.

Findings for the second dependent measure, the Energy Expenditure Index, showed a similar curvilinear pattern after controls for social background factors were introduced, $\beta=.14, F(4,23)=2.80, p<.05$. That is, middle-aged men were less active than their younger and older counterparts. Again, the relationship between age and activity was not significant after controls for social background factors and health status were introduced, $\beta=$ $.11, F(4,27)=1.84, p<.05$.

After each set of controls, the findings for the relationship between age and involvement in organized physical activity were slightly curvilinear, although young men were the most active: $\beta=.12, F(4,23)=3.21, p<.05$ at the first level of controls and $\beta=.13, F(4,27)=3.71, p<.05$ at the second level of controls. Respondents between the ages of 35 and 65 were the least involved in organized physical activity, and levels of organized involvement were higher for those over the age of 65 , but not at the same levels as for the youngest age group. The level of organized activity of the older age category increased with the control for social background factors, as would be expected if the effects of the latter tended to suppress the activity of older people. The same did not occur for the other two measures of activity.

Table 2 shows the comparable analyses for adult women. Here, age was not a significant predictor of involvement in physical activity for any of the three measures after the first set of controls was introduced: $\beta=.06, F(4,23)=1.36 ; \beta$ $=.07, F(4,23)=1.55$; and $\beta=.09, F(4,23)=2.24$, respectively. Also, there were no discernible differences in patterns of activity across the age groups for women after the control for health status was added.

Comparing Tables 1 and 2 (i.e., comparing the zero-order, uncontrolled analyses), we see the pattern familiar from previous studies of lower activity by women than men. This is true for comparisons of most of the five age subgroups for the first two measures of activity. However, comparisons for the Organized Activity Index show either equivalent scores for the genders or higher scores for women. Thus, physical activity is more likely to be organized activity for some age groups of women, in a way that it is not for their counterpart men.

In sum, effects of the social background and health factors are implicated to some extent in explanations of the age-group differences among men, but not among women, for whom there are not age differences before or after controls for any of the indicators of physical activity were introduced. 


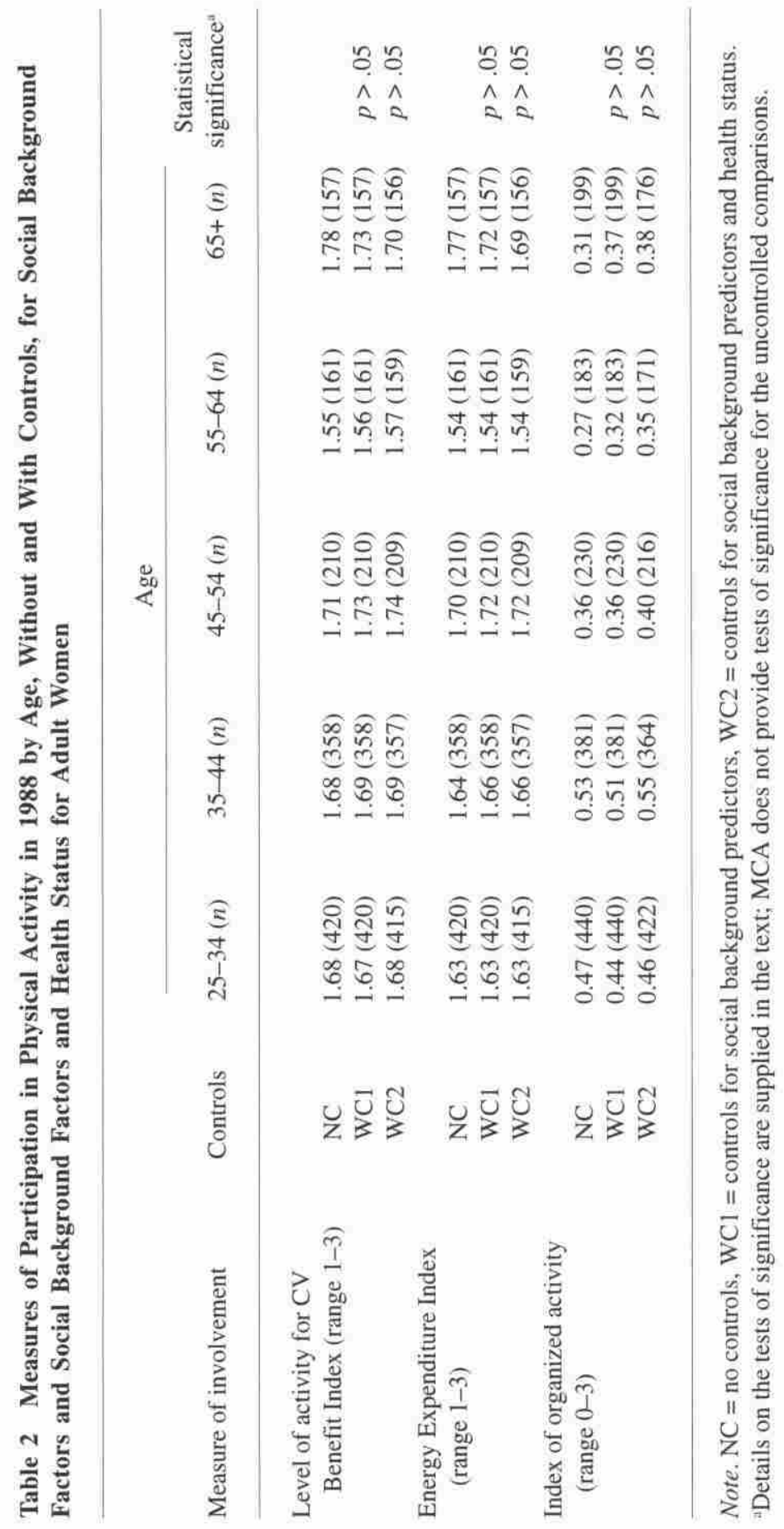




\section{RELATIVE EFFECTS OF AGE AND THE CONTROL VARIABLES IN 1988}

Beta coefficients (not reported here, to save space) yielded by the MCA procedure indicate the relative predictive strength of the independent and control variables. At the first level of controls in Table 1, for men, age was either the strongest or the second-strongest predictor of the physical activity involvement measures, $\beta=.14$, $F(4,23)=2.76, p<.05 ; \beta=.14, F(4,23)=2.80, p<.05$; and $\beta=.12, F(4,23)=$ $3.21, p<.05$, respectively, for the three measures of activity. Only income was a stronger predictor of level of activity for cardiovascular benefit, $\beta=.17, F(6,23)$ $=3.34, p<.01$, and energy expenditure, $\beta=.17, F(6,23)=3.39, p<.01$. For these two dependent measures the remaining control variables were not statistically significant predictors after controls were introduced. Education was the only other significant predictor of organized activity, $\beta=.12, F(5,23)=3.31, p<.01$, beyond age, $\beta=.12, F(4,23)=3.21, p<.05$, in the first level of controls. At the second level of controls, health status was the strongest predictor, $\beta=.18, F(4,27)=9.18, p<$ .001 , and $\beta=.18, F(4,27)=8.86, p<.001$, for both the Cardiovascular Benefit Index and the Energy Expenditure Index. Beyond this, only income remained significantly related to these two measures of physical activity involvement after controls, $\beta=.14, F(6,27)=2.31, p<.05$, and $\beta=.14, F(6,27)=2.40, p<.05$. For participation in organized activity, age and education were the strongest predictors after the additional control for health status was introduced, $\beta=.13, F(4,27)=3.71, p<.01$, and $\beta=.13, F(5,27)=3.70, p<.01$. In the controlled analyses, the relationships for income, education, and health were positive in direction.

Among the control variables employed in the analyses for women (Table 2), province, $\beta=.12, F(4,23)=4.74, p<.001$, and $\beta=.12, F(4,23)=4.89, p<.001$; education, $\beta=.12, F(5,23)=3.14$, and $\beta=.11, F(5,23) 2.53, p<.05$; and employment status in $1988, \beta=.12, F(1,23)=10.36, p<.001$, and $\beta=.12, F(1$, $23)=10.51, p<.001$, were all significant predictors of the Index of Activity Necessary for Cardiovascular Benefit and the Energy Expenditure Index after the first set of controls was introduced. Their importance in prediction was relatively equal for both stages of analysis. More highly active female respondents were more likely to live in western Canada, to be more educated, and to not be employed. After the second set of controls was introduced, health status was the strongest predictor of these two dependent measures, $\beta=.15, F(4,27)=7.76, p<.001$, and $\beta=.15$, $F(4,27)=7.67, p<.001$. As we have seen, age was not a significant predictor. Income was the only significant predictor of organized activity after the first set of controls was introduced, $\beta=.13, F(6,23)=2.86, p<.01$. After the additional control for health status was introduced, $\beta=.11, F(4,27)=4.19, p<.01$, income remained a positive and significant predictor of organized physical activity, $\beta=.12, F(6,27)$ $=2.54, p<.05$.

\section{CHANGES IN PHYSICAL ACTIVITY INVOLVEMENT, 1981-1988, BY AGE}

Findings for changes in levels of activity for men from 1981 to 1988 are shown in Table 3 . Both measures of change in physical activity involvement were significantly associated with age, $\beta=.16, F(4,23)=3.77, p<.01$, and $\beta=.17, F(4,23)$ $=4.13, p<.01$, respectively, for the first set of controls, and $\beta=.15, F(4,27)=3.51$, $p<.01$, and $\beta=.16, F(4,27)=3.88, p<.01$, respectively, for the second set of 


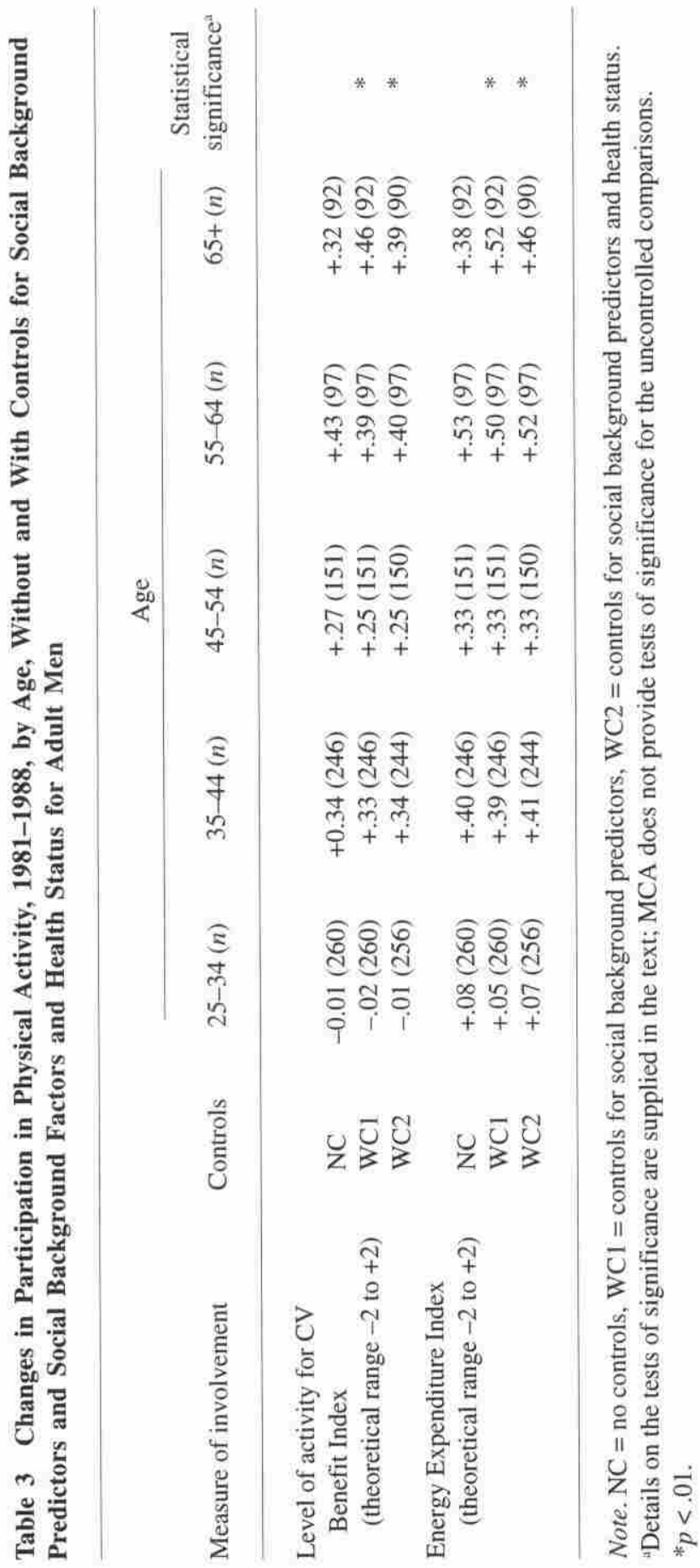


controls. There was a general pattern of increased activity from 1981 to 1988 , although the amount of change varied by age category.

After controls were introduced, findings for the Index of Activity for Cardiovascular Benefit indicated that the increase in activity from 1981 to 1988 was greatest among the older respondents and smallest in the youngest age category (in which there was a small decline of reported activity). Similar findings occurred for the Energy Expenditure Index. After controls were introduced, activity levels increased in 1988 for all respondents, but the greatest increase was for respondents older than 55 years of age. Comparing the uncontrolled and controlled analyses shows that the patterns of change by age were little affected by the controls.

The comparable findings for women (shown in Table 4) indicate that, as was the case for men, respondents generally reported that they were more involved in physical activity in 1988 than they had been in 1981. However, the patterns by age were different for women. Before and after controls were introduced, increases in physical activity on both measures from 1981 to 1988 were greatest for women aged 45-54 years. After controls were introduced, the next-highest reported increase in activity was for women aged 35-44. In general, there was a curvilinear relationship between age and changes in level of activity from 1981 to 1988 , with middle-aged women reporting greater increases in activity. These patterns were statistically significant for the Index of Activity for Cardiovascular Benefit, $\beta=.10, F(4,23)=$ $2.49, p<.05$, with the first set of controls, and $\beta=.11, F(4,27)=2.50, p<.05$, for the second level of controls and for the second level of controls for the Energy Expenditure Index, $\beta=.10, F(4,27)=2.44, p<.05$, for the first level of controls, $\beta=.10, F(4,23)=2.31, p>.05$. As with the data for men, the patterns of change by age showed little impact from effects of the control variables.

Across-gender comparison of the uncontrolled results in Tables 3 and 4 indicates that the increase in activity from 1981 to 1988 was greater for men than for women in the 55-65-year-old subgroup. Beyond this, there was little gender difference in the patterns of change in activity over the study period. When one gender in the age categories increased activity, the other tended to also do so in a similar manner.

\section{RELATIVE EFFECTS OF AGE AND THE CONTROL VARIABLES FOR CHANGES, 1981-1988}

In the results for men, age and income were the only two significant predictors of both measures of change after the first set of controls. The strength of their effects was comparable for both the Index of Activity Necessary for Cardiovascular Benefit, $\beta=.16, F(4,23)=3.77, p<.01$, and $\beta=.17, F(6,23)=2.99, p<.01$, and the Energy Expenditure Index, $\beta=.17, F(4,23)=4.13, p<.01$, and $\beta=.15, F(6$, $23)=2.55, p<.05$. They remained the strongest, and significant, predictors after the addition of health status as a control, $\beta=.15, F(4,27)=3.51, p<.05$, and $\beta=.15$, $F(4,27)=2.43, p<.05$, for the Index of Activity Necessary for Cardiovascular Benefit, $\beta=.16, F(4,27)=3.88, p<.01$, and $\beta=.13, F(6,27)=2.12, p<.05$, for the Energy Expenditure Index.

Among women, age was the only significant predictor of change in level of activity for cardiovascular benefit at both levels of controls, $\beta=10, F(4,23)=2.49$, $p<.05$, and $\beta=.11, F(4,27)=2.50, p<.05$. For the second measure of change, using 


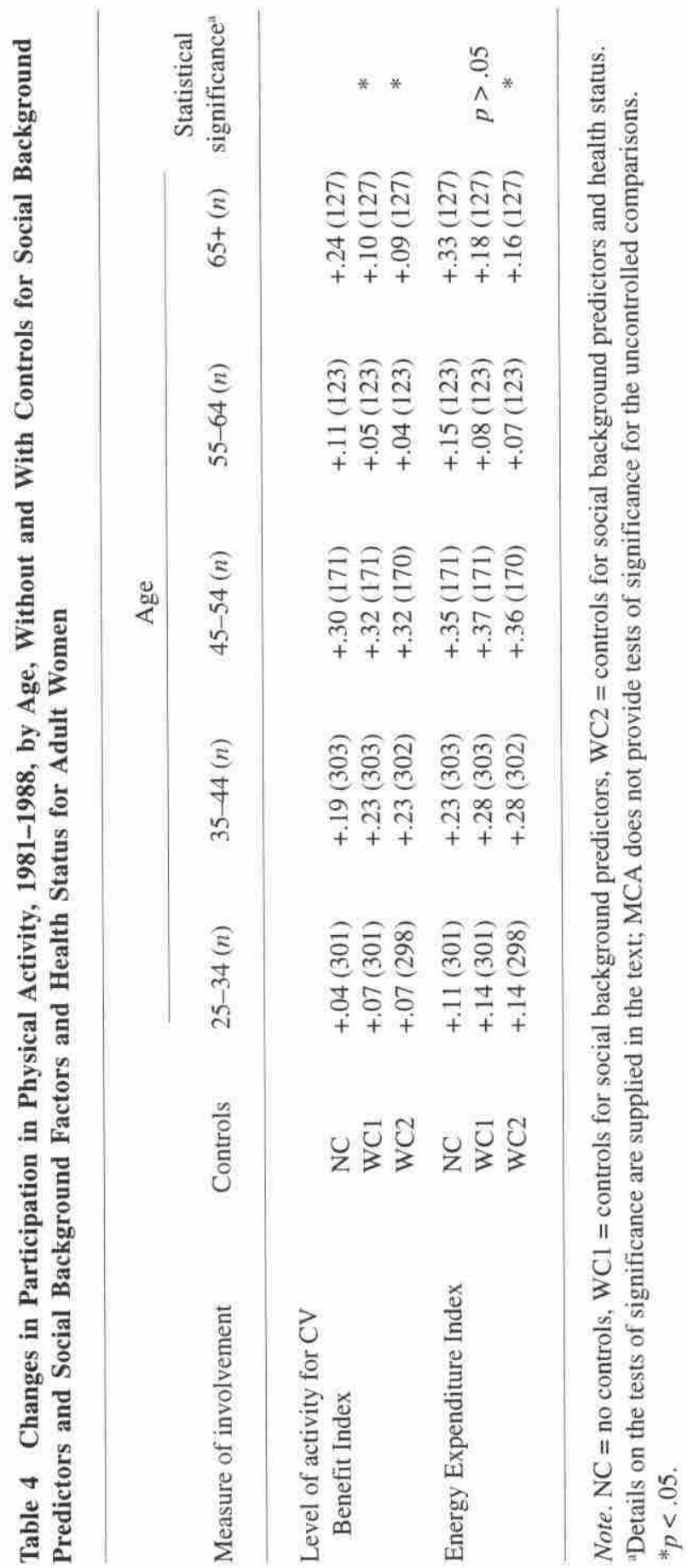


the Energy Expenditure Index, age was only significant at the second level of controls, $\beta=.10, F(4,27)=2.44, p<.05$, for the first level of controls, $\beta=.10, F(4$, $23)=2.31, p>.05$. None of the other variables was a significant predictor of change on this index except for employment status, which was significant at both the first level, $\beta=.11, F(1,23)=6.50, p<.05$, and the second level, $\beta=.11, F(1,27)=7.02$, $p<.01$, of controls. Women not working in 1988 were more likely to have increased energy expenditure in leisure-time physical activity since 1981.

\section{Discussion}

In recent years, sedentary living has been identified as a serious health hazard, of the same magnitude as smoking, high blood pressure, and high cholesterol (e.g., Olshansky, Carnes, \& Cassel, 1993). As a risk factor deemed to be one of the easiest to modify, physical activity has become a strong concern of government and other agencies attempting to improve the population's health (e.g., Fitness Canada, 1992; Russell, 1997). For example, in the United States, the 1996 Surgeon General's Report on Physical Activity and Health suggested that "significant health benefits can be obtained by including a moderate amount of physical activity (e.g., 30 minutes of brisk walking or raking leaves) on most, if not all, days of the week" (U.S. Department of Health and Human Services, 1996, p. 11).

The results of the present study provide some reasons for optimism. The panel data for Canada yielded positive findings of increased physical activity over the study period for most age and gender subgroups. These findings, it should be remembered, bear directly on longitudinal change during the period, they are generalizable to the population, and they are free of the confounding effects of several social background characteristics that were controlled for in the analyses. That is, the age-group changes do not result from conjoint effects of socioeconomic status or other social background factors, although income, education, and employment status did have independent effects on change in activity.

The findings show that, with the partial exception of young adults, Canadians of all age/gender subgroups increased their levels of leisure-time physical activity between 1981 and 1988. Changes in level of activity, though, varied both by age and by gender. There were greater increases in activity among Canadian men over the age of 55 than among their younger and middle-aged counterparts. Among women it was the middle-aged respondents who increased their activity the most. Women aged 35-54 showed the greatest increase in participation from 1981 to 1988. Younger and older women were also more involved over time.

These age and gender differences in activity over the period are difficult to interpret. There are several possible interpretations, all of which must remain hypotheses for the time being, requiring further study. Before suggesting interpretations, we should note that the results have parallels in some other studies. For example, Chogahara and Yamaguchi (1998) recently reported on patterns of increased leisure-time physical activity with age among a convenience sample of older people in Japan (see also Malina, 1996; Sallis \& Hovel, 1990). Chogahara and Yamaguchi point out that the

recent increase in physical activity with aging cannot be explained by traditional gerontological theories ... because these theories are limited to 
accounts of dynamic behavioral changes with aging. ... Most studies have examined the issue of activity and continuity or disengagement patterns of physical activity among the elderly; little is known about the new acquisition or resumption pattern of physical activity. (p. 278)

Chogahara and Yamaguchi (1998) go on to emphasize that continuity theory, which posits that "later life is a continuation of a person's past and that in the later years people will choose the lifestyle most like the pattern of life they lived in middle age" (p. 279), no longer gives sound purchase on the study of physical activity, because people often change their behavior either to begin activity or to increase activity. Rather, Chogahara and Yamaguchi propose that we apply the idea of resocialization to older people. This involves "basic and often rapid change in behavior in response to an altered social situation" (p. 278). In terms of physical activity, people are resocialized when they have a fundamental change in beliefs, attitudes, and circumstances, causing them to adopt a program of physical activity or increase their activity level.

Consistent with this approach are the following possible interpretations of the patterns of change found in this study. The findings for men, for whom the greatest increases were among the older age cohorts, might be explained by changing life circumstances characteristic of those groups. Older men, some of whom have retired from work or for whom work has become less central to their lives, have more time, energy, and other resources to devote to nonwork activities. Changed routines and shifting statuses might be significant enough for older men to reprioritize physical activity in their lives. Furthermore, this shift might be shared by sufficiently large numbers that supportive social networks develop in order to help sustain physical activity involvement. Perhaps, too, media campaigns on the importance of increased activity for health and increased availability of facilities and programs for seniors are implicated in the resocialization to increased physical activity.

The findings for women, for whom increases in activity were greatest among the middle-aged, clearly suggest that the processes of resocialization to activity vary not only by age but also by gender. Different dynamics were apparently at play for women than for men over the time period studied. One possible interpretation of the pattern of change for women is that as publicity and public knowledge about the preventive effects of exercise for osteoporosis became more widespread during the 1980 s, this led to higher levels of activity among middle-aged women. Also, the pursuit of slimness among women through exercise became more normative during the 1980 s, along with greater acceptance of women's involvement in sport and physical activity. Women in their middle years might have been more susceptible to pervasive messages linking exercise to weight loss than were younger and older women, and they also might have had more resources (time, money, and opportunities) to devote to physical activity.

In the cross-sectional data, the finding from various studies in the literature of an inverse relationship between age and level of involvement in physical activity was not evident for two of the three measures. On the measures of levels of activity necessary for health benefits, activity among Canadians over the age of 65 was as high as, or higher than, among younger Canadians, for both men and women. It is unclear whether the contradiction with previous results indicates that there has been 
significant social change around the age-activity relationship, or whether our measures of activity tap different components of the activities of older people than other measures of activity - each is possible. It will take further study, comparing across measures, to clarify the situation. It is possible that measures employed in much of the previous research have been biased toward types of activity that are more normative for younger adults than is the case for the measures in the two Canadian surveys. This would occur, for example, if other measures excluded activities such as social dancing, hiking, and walking for exercise, which are more common among older people and were included in the present measures. Also, when responding to survey questions about physical activities, young people might be less likely than older people to consider these types of activity physical activities and less likely to report that they participate in such activities.

Further work should also, whenever possible, employ measures of levels of physical activity in general, whether the activity is at leisure or at work. This issue of attending to leisure and work contexts has been emphasized with reference to the study of occupational status and physical activity. People who labor at physically demanding jobs often see meaningful leisure as involving liberation from physical effort, whereas nonlaborers are more likely to seek out physically strenuous leisuretime activities for variety, because these are lacking in their work (see, e.g., White \& Young, 1995).

Although there is a voluminous literature identifying positive consequences of physical activity for health (e.g., Bouchard et al., 1990, 1994; Curtis \& Russell, 1996), considerably more research must be conducted before definitive prescriptive statements can be made, particularly in terms of how they should be specified by age and gender. There are grounds for caution in this regard, given the differing relationships of physical activity with age and with gender. However, as we have indicated, there is reason for optimism. The data for the 1981-88 period in Canada clearly suggest that physical activity increased for various social subgroups and did not decline for others. Hopefully, we will be able to assess other panel data for the 1990 s and into the next century, to determine whether the trend continues, and to better specify the sources of change in activity levels.

\section{References}

Andrews, F., Morgan, J., Sonquist, J., \& Klein, L. (1973). Multiple classification analysis. Ann Arbor, MI: Institute for Social Research.

Blair, S.N., Brill, P.A., \& Barlow, C.E. (1994). Physical activity and disease prevention. In H. Quinney, L. Gauvin, \& A.E. Ted Wall (Eds.), Toward active living: Proceedings of the International Conference on Physical Activity, Fitness, and Health (pp. 25-31). Champaign, IL: Human Kinetics.

Bokovoy, J., \& Blair, S. (1994). Aging and exercise: A health perspective. Journal of Aging and Physical Activity, 2, 243-260.

Bouchard, C., Shephard, R.J., \& Stephens, T. (Eds.). (1994). Physical activity, fitness, and health. International proceedings and consensus statements. Champaign, $\mathrm{L}$ : Human Kinetics. 
Bouchard, C., Shephard, R.J., Stephens, T., Sutton, J.R., \& McPherson, B.D. (Eds.). (1990). Exercise, fitness, and health: A consensus of current knowledge. Champaign, IL: Human Kinetics.

Buskirk, E. (1990). Exercise, fitness, and aging. In C. Bouchard, R.J. Shephard, T. Stephens, J.R. Sutton, \& B.D. McPherson (Eds.), Exercise, fitness, and health: A consensus of current knowledge (pp. 687-697). Champaign, IL: Human Kinetics.

Chogahara, M., \& Yamaguchi, Y. (1998). Resocialization and continuity of involvement in physical activity among elderly Japanese. International Review for the Sociology of Sport, 33, 277- 289.

Clark, D. (1995). Racial and educational differences in physical activity among older adults. The Gerontologist, 35, 472-480.

Curtis, J., \& McPherson, B. (1987). Regional differences in leisure physical activity of Canadians: Testing some alternative interpretations. Sociology of Sport Journal, 4, 363-375.

Curtis, J., \& Russell, S. (Eds.). (1996). Physical activity in human experience: Interdisciplinary perspectives. Champaign IL: Human Kinetics.

Curtis, J., \& White, P. (1984). Age and sport participation: Decline in participation or increased specialization with age? In P. Donnelly \& N. Theberge (Eds.), Sport and the sociological imagination (pp. 273-293). Fort Worth, TX: Texas Christian University Press.

Drinkwater, B. (1994). Physical activity and health outcomes in women. In H. Quinney, L. Gauvin, \& A.E. Ted Wall (Eds.), Toward active living: Proceedings of the International Conference on Physical Activity, Fitness, and Health (pp. 33-38). Champaign, IL: Human Kinetics.

Dumazedier, J. (1973). Report to a symposium on sport and age. In O. Grupe, D. Kurz, \& J.M. Teipel (Eds.), Sport in the modern world-Chances and problems (pp. 198-199). New York: Springer Verlag.

Fitness Canada (1992). A fit third age. Ottawa: Secretariat for Fitness in the Third Age, Government of Canada.

Fletcher, P.C., \& Hirdes, J.P. (1996). A longitudinal study of physical activity and self-rated health in Canadians over 55 years of age. Journal of Aging and Physical Activity, 4, 136-150.

Hagberg, J. (1994). Physical activity, fitness, health, and aging. In C. Bouchard, R.J. Shephard, \& T. Stephens (Eds.), Physical activity, fitness, and health. International proceedings and consensus statements (pp. 993-1005). Champaign, IL: Human Kinetics.

Haskell, W., Montoye, H., \& Orenstein, D. (1985). Physical activity and exercise to achieve health-related components of physical fitness. Public Health Reports, 100, 202-212.

Hobart, C.W. (1975). Active sports participation among the young, the middle-aged and the elderly. International Review of Sport Sociology, 10, 27-40.

Lock, J., \& Wister, A. (1992). Intentions and changes in exercise and behaviour: A life-style perspective. Health Promotion International, 7, 195-208.

Malina, R. (1994). Benefits of physical activity from a lifetime perspective. In H. Quinney, L. Gauvin, \& A.E. Ted Wall (Eds.), Toward active living: Proceedings of the International Conference on Physical Activity, Fitness, and Health (pp. 47-53). Champaign IL: Human Kinetics. 
Malina, R. (1996). Tracking of physical activity and physical fitness across the lifespan. Research Quarterly for Exercise and Sport, 67 (suppl.), 48-57.

McAuley, E. (1994). Enhancing psychological health through physical activity. In H. Quinney, L. Gauvin, \& A.E. Ted Wall (Eds.), Toward active living: Proceedings of the International Conference on Physical Activity, Fitness, and Health (pp. 83-90). Champaign, IL: Human Kinetics.

McPherson, B. (1978). Aging and involvement in physical activity: A sociological perspective. In F. Landry \& W. Orban (Eds.), Physical activity and human well-being (Vol. 1, pp. 111-128). Miami, FL: Symposium Specialists.

McPherson, B. (1998). Aging as a social process: An introduction to individual and population aging ( $3 \mathrm{rd}$ ed.). Toronto: Harcourt Brace.

McPherson, B., \& Kozlik, C. (1987). Age patterns in leisure participation: The Canadian case. In V. Marshall (Ed.), Aging in Canada: Social perspectives (pp. 211-227). Markham, ON, Canada: Fitzhenry and Whiteside.

O'Brien Cousins, S., \& Keating, N. (1995). Life cycle patterns of physical activity among sedentary and active older women. Journal of Aging and Physical Activity, 3, 340-359.

Olshansky, S., Carnes, B., \& Cassel, C. (1993). The aging of the human species. Scientific American, 268, 46-52.

Orban, W. (1991). Healthy, happy aging. Burnstown, ON, Canada: General Store Publishing House,

Paffenbarger, R.S., Jr., Hyde, R.T., Wing, A.L., Lee, I-M., \& Kampert, J.B. (1994). An active and fit way-of-life influencing health and longevity. In H. Quinney, L. Gauvin, \& A.E. Ted Wall (Eds.), Toward active living: Proceedings of the International Conference on Physical Activity, Fitness, and Health (pp. 61-68). Champaign, IL: Human Kinetics.

Quinney, H., Gauvin, L., \& Ted Wall, A.E.(Eds.).(1994). Toward active living: Proceedings of the International Conference on Physical Activity, Fitness, and Health. Champaign, IL: Human Kinetics.

Russell, S. (1997). Active living among older Canadians: Trends and directions for action. Ottawa: Canadian Fitness and Lifestyle Research Institute.

Sallis, J., \& Hovel, M. (1990). Determinants of exercise behavior. Exercise and Sport Sciences Review, 18, 307-333.

Spirduso, W. (1994). Physical activity and aging: Retrospections and visions for the future. Journal of Aging and Physical Activity, 2, 233-242.

Spirduso, W. (1995). Physical dimensions of aging. Champaign, IL: Human Kinetics.

Stephens, T., \& Caspersen, C. (1994). The demography of physical activity. In C. Bouchard, R.J. Shephard, \& T. Stephens (Eds.), Physical activity, fitness and health: International proceedings and consensus statement (pp. 204-213). Champaign, IL: Human Kinetics.

Stephens, T., \& Craig, C. (1985, June). Fitness and activity measurement in the 1981 Canada Fitness Survey. Proceedings of the workshop on assessing physical fitness and activity patterns in general population surveys. Ottawa, ON, Canada: Canadian Fitness and Lifestyle Research Institute.

Stephens, T., \& Craig, C. (1990). The well-being of Canadians: Highlights of the 1988 Campbell's Survey. Ottawa: Canadian Fitness and Lifestyle Research Institute. 
Stephens, T., Craig, C., \& Ferris, B. (1986). Adult physical activity in Canada: Findings from the Canada Fitness Survey I. Canadian Journal of Public Health, 77, 285-290.

U.S. Department of Health and Human Services. (1996). Physical activity and health: A report of the Surgeon General. Washington, DC: Centers for Disease Control and Prevention.

White, P., \& Curtis, J. (1990). Participation in competitive sport among anglophones and francophones in Canada: Testing competing hypotheses. International Review for the Sociology of Sport, 25, 125-141.

White, P., \& Young, K. (1995). Bodywork as a moral imperative: Some critical notes on health and fitness. Loisir et Société, 18, 159-182.

\section{Acknowledgment}

We gratefully acknowledge that this research was funded by a grant from the Arts Research Board, McMaster University, and that computing support was provided by the University of Waterloo. We also thank Terry Stewart, University of Waterloo, for his assistance with the analysis of the data, and John Hirdes, University of Waterloo, for helpful suggestions. 